\title{
Individual meaning in life assessed with the Schedule for Meaning in Life Evaluation: toward a circumplex meaning model
}

\author{
MARTIN FEGG, PH.D., ${ }^{1}$ DOROTHEA KUDLA, M.D. ${ }^{1}$ MONIKA BRANDSTÄTTER, PH.D., ${ }^{1}$ \\ VERONIKA DEFFNER, DIPL.STAT., ${ }^{2}$ AND HELMUT KÜCHENHOFF, PH.D. ${ }^{2}$ \\ ${ }^{1}$ Department of Palliative Medicine, Ludwig Maximilian University of Munich, Munich, Germany \\ ${ }^{2}$ Statistical Consulting Unit, Department of Statistics, Ludwig Maximilian University of Munich, Munich, Germany \\ (RECEIVEd December 22, 2014; ACCEPTEd April 19, 2015)
}

\begin{abstract}
Objective: The experience of "meaning in life" (MiL) is a major aspect of life satisfaction and psychological well-being. To assess this highly individual construct, idiographic measures with open-response formats have been developed. However, it can be challenging to categorize these individual experiences for interindividual comparisons. Our study aimed to derive MiL categories from individual listings and develop an integrative MiL model.

Method: University students were asked to rate $58 \mathrm{MiL}$ providing aspects recently found in a nationwide study using the Schedule for Meaning in Life Evaluation (SMiLE), an MiL instrument allowing for open responses. Pearson's correlations and factor analyses were used to test the unidimensionality of subsequently derived higher-order MiL categories.

Multidimensional scaling, cluster analysis, and factor analysis were performed to further analyze a latent MiL structure.

Results: A total of 340 students participated in the study. Some 11 unidimensional categories consisting of 34 meaning-providing aspects were summarized into a circumplex model with four MiL domains: leisure/health, work/finances, culture/spirituality, and relationships (family, partnership, social relations).

Significance of results: This model seems to incorporate a major portion of individual respondent-generated MiL listings. It may be useful for future idiographic MiL studies to help organize individual experiences of MiL and allow for higher-level interindividual comparisons. Further studies including different samples are necessary to confirm this model or derive other MiL domains, for example, in palliative care patients or patients who are confronted with a loss of meaning.
\end{abstract}

KEYWORDS: Meaning in life, SMiLE, Structure of meaning in life, Cluster analysis, Multidimensional scaling

\section{INTRODUCTION}

Meaning in life (MiL) experience has been shown to be an important aspect of psychological well-being in healthy individuals as well as in cancer and palliative care patients (Lethborg et al., 2007; McKnight \& Kashdan, 2009). MiL can be defined as "the

Address correspondence and reprint requests to Martin Fegg, Marchioninistr. 15, 81377 Munich, Germany, Phone +49-8924216130, Fax +49-89-24216135, E-mail: martin@fegg.de. Website: www.meaninginlife.info. cognizance of order, coherence, and purpose in one's existence, the pursuit and attainment of worthwhile goals, and an accompanying sense of fulfillment" (Wong \& Fry, 1998, p. 41); thus, it comprises a cognitive and a motivational component (providing a framework for meaning), and an emotional component (fulfillment) (Brandstätter et al., 2012). Several studies have shown that a loss of MiL entails psychological distress and even requests for euthanasia in patients suffering from incurable diseases (Kissane et al., 2001; Meier et al., 1998; Moadel et al., 1999). 
Therefore, psychological interventions have been developed to sustain or enhance MiL in palliative care patients (Breitbart et al., 2010; Chochinov et al., 2005) as well as in healthy subjects suffering from loss of meaning (Frankl, 1958).

In a systematic review, 59 different instruments for assessment of MiL were found and differentiated into nomothetic (quantitative/deductive) and idiographic (free responses/inductive) approaches (Brandstätter et al., 2012). Nomothetic instruments present either theoretically derived a-priori categories or categories inductively derived from previous studies, but disregard further individual aspects of MiL experience. Therefore, researchers developed idiographic, openresponse instruments allowing for assessment of individual MiL experiences. However, it can be challenging to categorize these individual experiences for interindividual comparisons.

In philosophy, there has been a longstanding debate around predefined categories and the construction of individual meaning dimensions: in this nominalism debate, rationalists propose existing categories independent of individuals, while empiricists argue that categories are individually constructed (Rodriguez-Pereyra, 2008). In a pluralistic society, where traditional meaning beliefs have increasingly less impact, an individualized, idiographic approach may be especially suited.

In the Schedule for Meaning in Life Evaluation (SMiLE), an idiographic instrument, respondents are asked to list individual areas that provide meaning to their life before rating their current level of satisfaction and the importance of each area (Fegg et al., 2008). The SMiLE therefore pursues a qualitative/ quantitative approach. It has been used to evaluate MiL in a representative sample of the German population (Fegg et al., 2007) as well as in palliative care, in patients suffering from amyotrophic lateral sclerosis, progressive supranuclear palsy, and cancer (Fegg et al., 2008; 2010; 2013; Stiefel et al., 2008). The psychometric properties of the SMiLE have been tested in several studies (Fegg et al., 2008; Stiefel et al., 2008).

To categorize the individual listings of a representative SMiLE survey (1004 subjects with a total of 3521 individual listings), 39 a-posteriori MiL aspects had been developed by independent raters (Fegg et al., 2007). Other studies using the SMiLE led to 19 additional aspects (58 meaning aspects in total; see Figure 1) (Kudla et al., 2014; Stiefel et al., 2008; Monforte-Royo et al., 2011; Brandstätter et al., 2014).

The aims of our study were (1) to identify unidimensional categories subsuming the MiL aspects listed in SMiLE studies so far and (2) to develop an integrative model of individual MiL experience based on these categories.

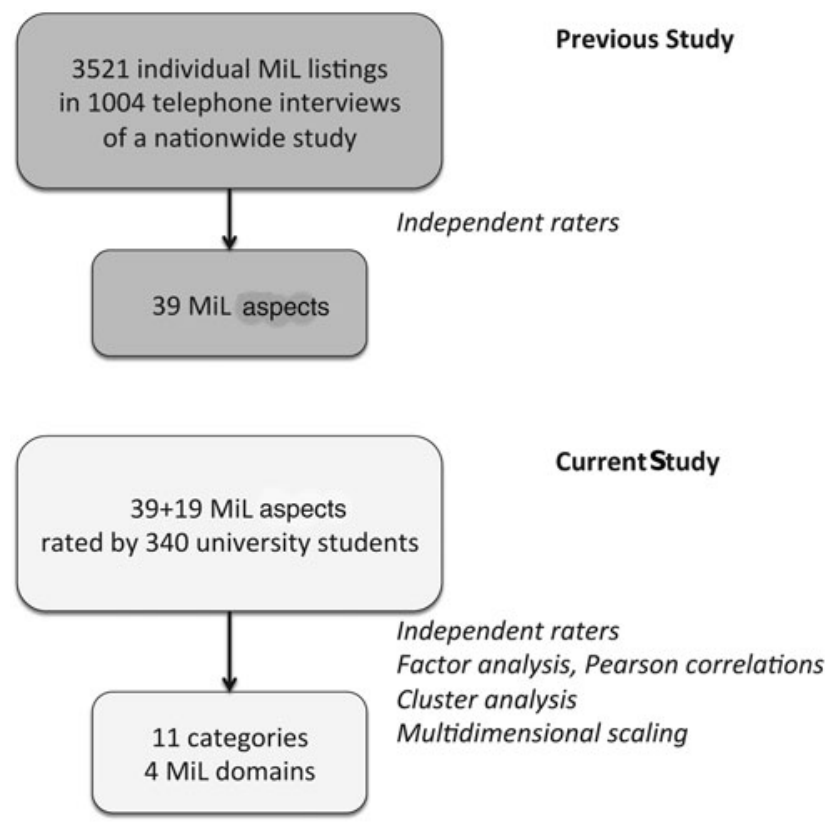

Fig. 1. Study design.

\section{METHODS}

\section{Study Design and Measures}

In this cross-sectional pilot study, all medical students attending a palliative care lecture were asked to participate. The study was conducted following the guidelines of the research ethics committee of the University of Munich.

The questionnaire consisted of $58 \mathrm{MiL}$ aspects that were found in previous SMiLE studies $(n=1004$, Figure 1). All students rated the importance of these aspects for their individual MiL on an 8-point adjectival scale ( 0 not important to 7 extremely important). Therefore, the individual framework (but not fulfillment) component of MiL was focused on in this study. To avoid biases resulting from individual response tendencies, the ratings were corrected for scale use through subtraction of each person's mean importance score from their single importance ratings (Schwartz et al., 1997). Thus, positive ratings indicate above-average importance, and negative ratings indicate lower importance ascribed to the single item compared to the averaged importance ratings of the respondent.

\section{Statistical Evaluation}

Pearson's correlations (in categories consisting of two items) and exploratory factor analysis with the principal components method (in categories consisting of three or more items) were utilized to test unidimensionality, that is, whether each category represents an independent part of MiL experience. 
Thereafter, multidimensional scaling (MDS) was used to visualize proximities of the categories in an integrative model. MDS reduces the multidimensional space between the different categories into a twodimensional map. Distances stand for observed between-object similarity: greater dissimilarity between two categories is shown by a larger distance between the two points representing these categories, and vice versa. The quality of MDS diagrams is expressed in its stress $(S)$. The smaller the stress, the better the quality of the representation. In this study, MDS maps were accepted if $S \leq 0.1$.

Hierarchical cluster analyses were employed to confirm the MDS findings and additionally investigate the similarity of MiL categories. The distances between different categories were calculated by average linkage between groups: categories with the smallest average distance to each other were combined into a new cluster.

PASW Statistics 17 and R 2.4.1 were used for statistical evaluations. Distances in the MDS analysis were calculated with PROXSCAL.

\section{RESULTS}

\section{Respondents' Characteristics}

A total of 340 medical students from the Ludwig Maximilian University of Munich took part in the study (response rate, $72.0 \%$ ). Some 33 students were excluded because of major incomplete responses (more than two thirds missing). Two items (children and grandchildren) were excluded because of extensive missing data. In total, data for 307 participants were analyzed (inclusion rate $=90.3 \%$ ). Missing data for the remaining items were imputed with the EM algorithm for incomplete categorical data (Schafer, 1996).

Table 1 provides an overview of the respondents' characteristics. The mean age of participants was $24.3 \pm 3.5$ years (range, $20-48$ years).

\section{Item Characteristics}

Table 2 shows the mean importance ratings of all MiL aspects. The most important aspects were family, health, love, parents, partnership, and friends, while the least important were garden, art, spirituality, religion, luxury, and pets (all in order of decreasing importance).

\section{Unidimensionality of Categories}

Two independent raters (VD, MF) developed 11 aposteriori categories out of these aspects in a feedback process of development and discussion with the other authors (Table 3): culture, family, finances,
Table 1. Respondents' characteristics $(N=307)$

\begin{tabular}{lr}
\hline \hline & $\%$ \\
\hline Sex & \\
Male & 34.8 \\
Female & 65.2 \\
Marital Status & \\
Single & 44.4 \\
In a relationship & 51.2 \\
Married & 4.3 \\
Denomination & \\
Catholic & 59.1 \\
Protestant & 24.0 \\
Non-denominational & 13.5 \\
Muslim & 3.1 \\
Buddhist & 0.3 \\
& \\
\hline \hline
\end{tabular}

health, hedonism, leisure, partnership, relaxation, social relations, spirituality and work. To represent independent aspects of MiL experience, these a-posteriori categories were tested for their unidimensionality: if they failed to be unidimensional, they were modified in an iterative process (discussion and review by VD, MF with factor analysis, Pearson correlation). During this process, some items were deleted (in the categories of finances, health, and culture), added (in the category of social relationship), or both (in the category of hedonism). Six categories did not have to be modified (family, partnership, work, leisure, relaxation, and spirituality), as they already met unidimensionality (Table 3 ).

The final model included 11 categories with 34 aspects. Pearson coefficients, scree plots and Kaiser criteria of exploratory factor analyses confirmed the unidimensionality of these categories. Explained variances of the first principal components of each category were above $40 \%$ (Table 3). Some 22 aspects (plus children and grandchildren) were not assigned to the categories and were not included in the further analyses (41.4\%). The internal consistency (Cronbach's alpha) of the categories can also be found in Table 3 .

\section{Multidimensional Scaling}

The proximities of the categories were analyzed with MDS. The MDS diagram (Figure 2) shows four areas in polar regions: (1) partnership, social relations, and family; (2) hedonism, leisure, relaxation, and health; (3) culture and spirituality; and (4) work and finances. Stress I (factor for best scaling $=1.004$ ) was 0.06 , Stress II (factor for best scaling $=1.004$ ) was 0.1 , and $S$ Stress (factor for best scaling $=1.001$ ) was 0.005 .

\section{Cluster Analysis}

To confirm the MDS findings and to identify clusters of categories in the MDS map, an additional cluster 
Table 2. Means (M) and standard deviations (SD) of the importance ratings of MiL aspects (corrected for scale use)

\begin{tabular}{|c|c|c|}
\hline \multirow[b]{2}{*}{ Item } & \multicolumn{2}{|c|}{$\begin{array}{c}\text { Importance } \\
\text { Rating } \\
(n=307)\end{array}$} \\
\hline & $M$ & $S D$ \\
\hline 1. Appearance & -0.94 & 1.32 \\
\hline 2. Art & -1.66 & 1.63 \\
\hline 3. Body & -0.08 & 1.05 \\
\hline 4. Children & - & - \\
\hline 5. Community & 0.25 & 1.14 \\
\hline 6. Creativity & -1.06 & 1.51 \\
\hline 7. Culture & -1.06 & 1.39 \\
\hline 8. Education & 0.76 & 1.06 \\
\hline 9. Enjoyment & 0.26 & 1.24 \\
\hline 10. Environment (interpersonal) & 0.80 & 1.04 \\
\hline 11. Expanding one's knowledge & 0.31 & 1.09 \\
\hline 12. Family & 1.46 & 1.00 \\
\hline 13. Finances & -0.64 & 1.34 \\
\hline 14. Financial security & 0.17 & 1.20 \\
\hline 15. Freedom & 0.85 & 1.16 \\
\hline 16. Friends & 1.19 & 0.94 \\
\hline 17. Future prospects & 0.98 & 0.94 \\
\hline 18. Garden & -1.63 & 1.71 \\
\hline 19. Good food & -0.30 & 1.50 \\
\hline 20. Grandchildren & - & - \\
\hline 21. Happiness & 0.85 & 1.17 \\
\hline 22. Harmony & 0.50 & 1.22 \\
\hline 23. Having fun & 0.13 & 1.27 \\
\hline 24. Health & 1.43 & 0.97 \\
\hline 25. Healthy diet & -0.33 & 1.38 \\
\hline 26. House/flat & -0.34 & 1.17 \\
\hline 27. Independence & 0.29 & 1.25 \\
\hline 28. Leisure activities & 0.04 & 1.27 \\
\hline 29. Life attitude & 0.66 & 1.05 \\
\hline 30. Literature & -0.97 & 1.47 \\
\hline 31. Love & 1.38 & 1.04 \\
\hline 32. Luxury & $-2,08$ & 1.53 \\
\hline 33. Money & -0.70 & 1.32 \\
\hline 34. Music & -0.39 & 1.59 \\
\hline 35. Nature & 0.07 & 1.29 \\
\hline 36. Parents & 1.23 & 1.21 \\
\hline 37. Partnership & 1.20 & 1.23 \\
\hline 38. Peace & 0.49 & 1.45 \\
\hline 39. Pets & $-2,22$ & 2,21 \\
\hline 40. Profession/work & 0.46 & 1.19 \\
\hline 41. Readiness to help others & 0.09 & 1.09 \\
\hline 42. Relatives & -0.19 & 1.57 \\
\hline 43. Relaxation & 0.14 & 1.17 \\
\hline 44. Religion & $-2,00$ & 2,12 \\
\hline 45. Satisfaction & 1.05 & 0.98 \\
\hline 56. School/studies/training & 0.66 & 1.01 \\
\hline 57. Security & 0.31 & 1.23 \\
\hline 58. Self realization & 0.28 & 1.19 \\
\hline 59. Sexuality & 0.31 & 1.25 \\
\hline 60. Siblings & 0.97 & 1.44 \\
\hline 61. Sociability & 0.13 & 1.24 \\
\hline 62. Social commitment & -0.75 & 1.37 \\
\hline 63. Spare time & 0.52 & 1.13 \\
\hline 64. Spirituality & -1.91 & 1.89 \\
\hline 65. Sport & 0.11 & 1.42 \\
\hline
\end{tabular}

Continued
Table 2. Continued

\begin{tabular}{|c|c|c|}
\hline \multirow[b]{2}{*}{ Item } & \multicolumn{2}{|c|}{$\begin{array}{c}\text { Importance } \\
\text { Rating } \\
(n=307)\end{array}$} \\
\hline & $M$ & $S D$ \\
\hline $\begin{array}{l}\text { 66. Success } \\
\text { 67. Traveling } \\
\text { 68. Wealth }\end{array}$ & $\begin{array}{l}-0.00 \\
-0.28 \\
-0.79\end{array}$ & $\begin{array}{l}1.32 \\
1.46 \\
1.32\end{array}$ \\
\hline
\end{tabular}

analysis was performed. The dendrogram in Figure 3 visualizes the similarity of category subgroups and provides the splits in the MDS map resulting in four distinct clusters.

In summary, cluster analysis and MDS of the MiL categories resulted in a circumplex model of MiL consisting of four domains (Figure 4): (1) relationships, (2) leisure/health, (3) culture/spirituality, and (4) work/finances.

\section{DISCUSSION}

In a representative German survey, the individual responses to an open-format MiL questionnaire were assigned to 39 a-posteriori aspects (Fegg et al., 2007). These aspects and 19 further aspects collected in additional studies were analyzed to identify a latent structure (Kudla et al., 2014; Stiefel et al., 2008; MonforteRoyo et al., 2011; Brandstätter et al., 2014). The final model comprised 11 independent higher-order MiL categories combined into a circumplex MiL model. This model consisted of four polar regions comprising $58.6 \%$ of all MiL aspects listed so far in studies using the SMiLE assessment: (1) relationships (including family, partner, and social relations); (2) leisure (including hedonism and relaxation) and health; (3) culture and spirituality; and (4) work and finances. The resulting four-quadrant model juxtaposes "relationships" versus "culture/spirituality" and "leisure/ health" versus "work/finances," indicating the dissimilarity of these domains in the two-dimensional space.

Other researchers used a predefined set of variables to assess MiL (DeVogler \& Ebersole, 1983; Ebersole \& DePaola, 1987; Yalom, 1980; Reker \& Wong, 1988): (1) relationships (to family members, partner, and friends); (2) hedonism/leisure activities/hobbies; (3) creativity (art/music); (4) belief/spirituality/religion; (5) material possessions; (6) altruism/service to others; and (7) self-realization/personal development. The last two categories were not reproduced in our study; work, home, health, and relaxation were additionally found. The current model results from a "bottom-up" approach, including individual responses to an idiographic MiL measure. 
Table 3. Eleven unidimensional categories. Excluded items are erossed out. Added items are in italics

\begin{tabular}{|c|c|c|c|c|c|}
\hline & Category & $\begin{array}{l}\text { Aspects Belonging to the } \\
\text { Category }\end{array}$ & $\begin{array}{l}\text { Cronbach's } \\
\text { Alpha }\end{array}$ & $\begin{array}{l}\text { Explained Variance (First } \\
\text { Eigenvalue or Pearson } \\
\text { Correlation) }\end{array}$ & $\begin{array}{l}\text { Explained Variance } \\
\text { (Second Eigenvalue) }\end{array}$ \\
\hline 1 & Culture & $\begin{array}{l}\text { art, creativity, culture, } \\
\text { literature, musie }\end{array}$ & 0.729 & $56.0 \%(2.239)$ & $21.9 \%(0.875)$ \\
\hline 2 & Family & $\begin{array}{l}\text { family, parents, relatives, } \\
\text { siblings }\end{array}$ & 0.571 & $47.4 \%(1.895)$ & $22.6 \%(0.903)$ \\
\hline 3 & Finances & $\begin{array}{l}\text { finances, financial security, } \\
\text { luxury, money, }\end{array}$ & 0.827 & $74.4 \%(2.231)$ & $17.8 \%(0.535)$ \\
\hline 4 & Health & $\begin{array}{l}\text { appearance, body, health, } \\
\text { healthy diet }\end{array}$ & 0.305 & $-(0.191)$ & - \\
\hline 5 & Hedonism & $\begin{array}{l}\text { enjoyment, good food, having } \\
\text { fun, sexuality }\end{array}$ & 0.484 & $50.1 \%(1.504)$ & $30.9 \%(0.926)$ \\
\hline 6 & Leisure & $\begin{array}{l}\text { leisure activities, spare time, } \\
\text { sport, traveling }\end{array}$ & 0.460 & $40.1 \%(1.606)$ & $25.4 \%(1.015)$ \\
\hline 7 & Partnership & love, partnership & 0.715 & $-(0.564)$ & - \\
\hline 8 & Relaxation & $\begin{array}{l}\text { having fun, relaxation, } \\
\text { satisfaction }\end{array}$ & 0.334 & $42.9 \%(1.287)$ & $30.3 \%(0.909)$ \\
\hline 9 & $\begin{array}{l}\text { Social } \\
\text { relations }\end{array}$ & $\begin{array}{l}\text { community, environment } \\
\text { (interpersonal), friends, } \\
\text { sociability }\end{array}$ & 0.500 & $40.8 \%(1.634)$ & $22.7 \%(0.906)$ \\
\hline 10 & Spirituality & religion, spirituality & 0.721 & $-(0.568)$ & - \\
\hline 11 & Work & $\begin{array}{l}\text { profession/work, school/ } \\
\text { studies/training, success }\end{array}$ & 0.592 & $55.3 \%(1.659)$ & $26.6 \%(0.799)$ \\
\hline
\end{tabular}

The number of content categories in other MiL studies varied from 7 to 13 (Brandstätter et al., 2012). There is considerable overlap between the meaning structure revealed in the current study and the categorization approaches applied by Prager (1996), Schnell (2009), Burbank (1992), and Takkinen and Ruoppila (2001). Other authors have developed distinctly different categorization schemes (Pohlmann et al., 2006; Wong, 1998; Debats, 1999; Dittmann-Kohli \& Westerhof, 1997; DeVogler \& Ebersole, 1980), most notably including categories like beliefs, growth, personal well-being, service, self-actualization, and self-transcendence. Other instruments cover similar meaning areas without

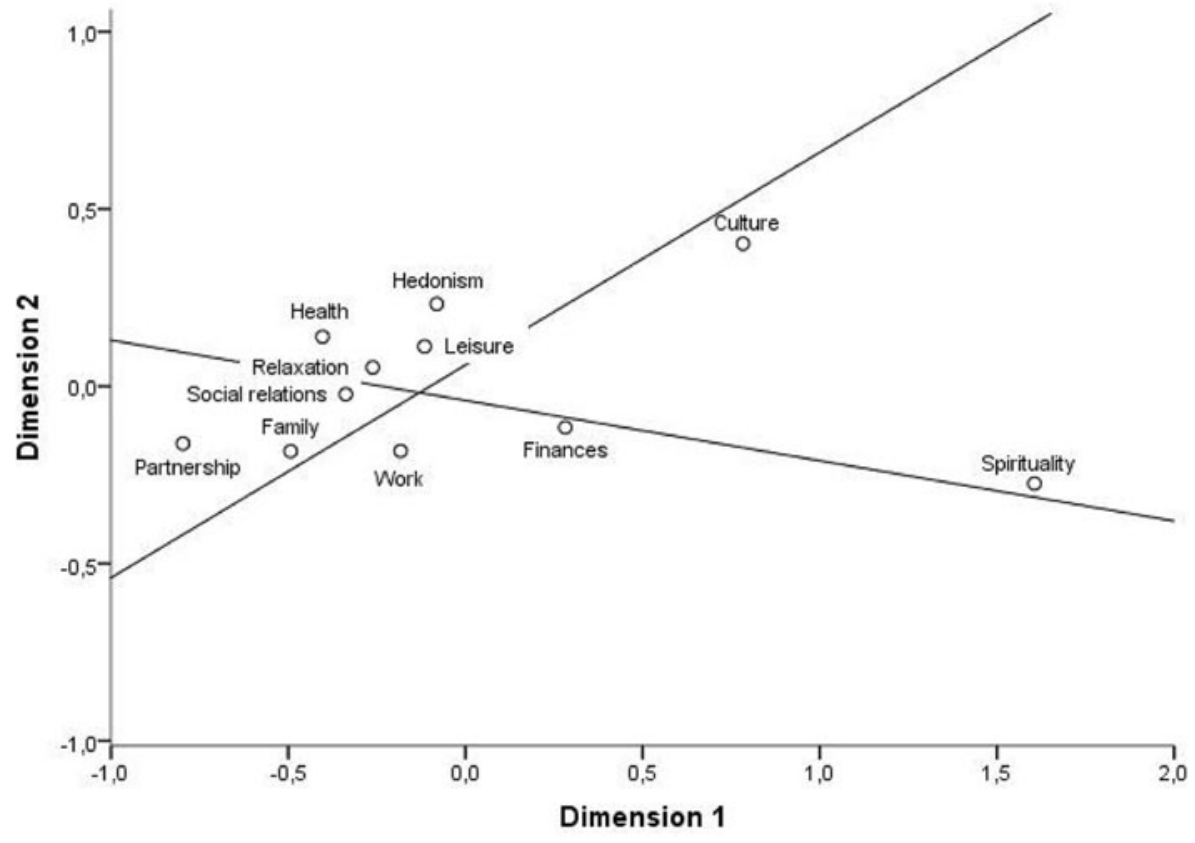

Fig. 2. Two-dimensional map of the 11 a posteriori categories (multidimensional scaling). 


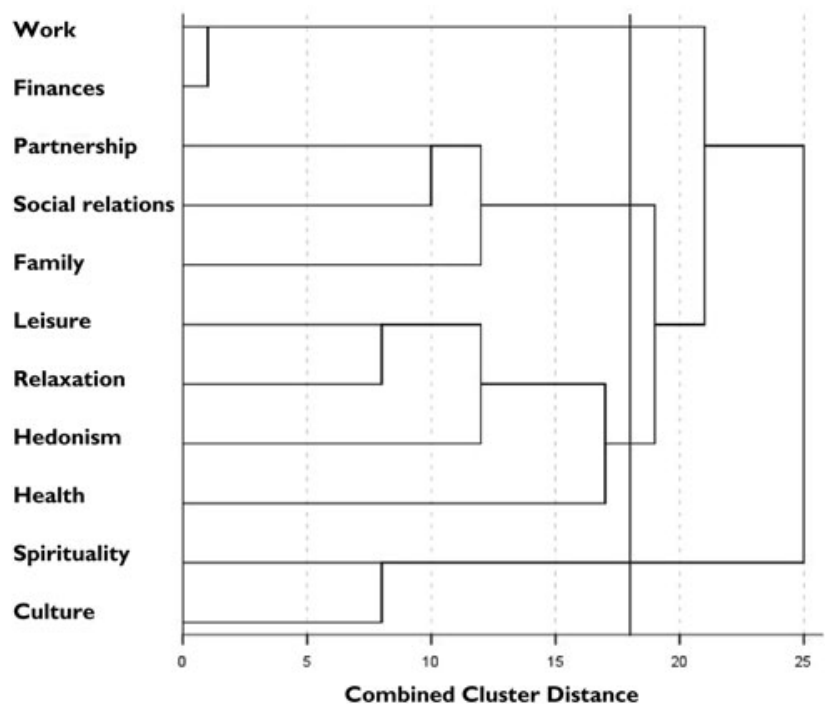

Fig. 3. Cluster analysis dendrogram of the 11 categories.

sorting them into categories (Prager, 1996; Kernes \& Kinnier, 2008). The areas of relationships and work/ achievement/life task seem to be common to most approaches.

Our study was based on the importance university students ascribed to each MiL aspect for their overall MiL experience. It is possible that all four domains need to be somewhat fulfilled to achieve a certain level of life satisfaction or meaning fulfillment. Future studies should therefore investigate whether all four domains need to be covered as a prerequisite for MiL fulfillment. Coping studies, however, show that critical life events seem to provoke a "response shift," for example, in patients suffering from incurable diseases (Sprangers \& Schwartz, 1999). Under extreme life circumstances (e.g., terminal disease),

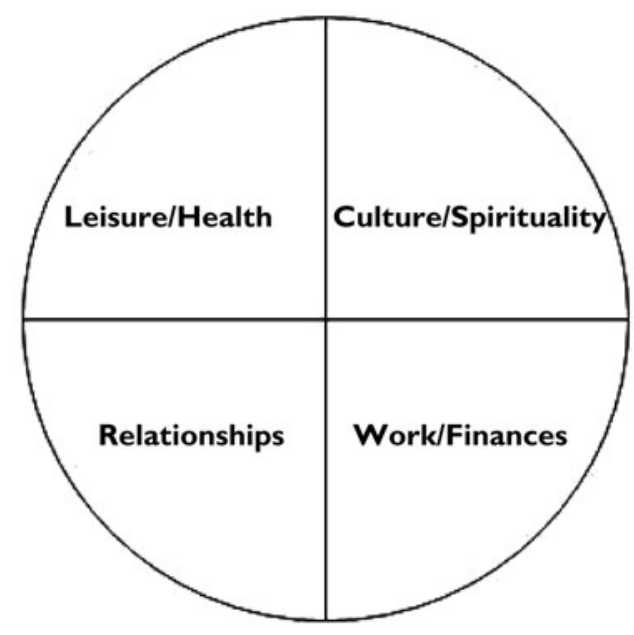

Fig. 4. Circumplex model of MiL experience. certain areas are focused upon by patients (e.g., close relationships), while other areas decrease in importance (e.g., wealth) (Fegg et al., 2008). Under these conditions, imbalances in the importance of the described MiL domains will arise during this adaptation process.

Our study has several limitations. The sample consisted of medical students with a specific educational level and age group. The findings are therefore not representative for healthy subjects or special populations (e.g., patient samples). We decided to test our method and statistical approach before enrolling a larger sample into a cost-intensive trial. Even in this particular sample, our results are comparable to other MiL studies. Two items (children and grandchildren) that had to be excluded might be subsumed into the category "family" in future investigations (Fegg et al., 2008).

Additional studies should investigate the validity of this model in other samples and add more dimensions if necessary. Studies should also include subjects suffering from meaning loss (e.g., palliative care patients and their caregivers) (Brandstätter et al., 2014). Furthermore, crosscultural designs including different countries, religions, and ethnicities could contribute to identifying potential universals in the experience of MiL. MiL aspects, categories, and domains may have to be amended in these contexts. A recent study using the SMiLE in India reported four additional culture-specific categories: passing on knowledge, social commitment, desires, and connection to community (Kudla et al., 2014).

An integrating MiL model may also be helpful in a psychotherapy context to support patients suffering from meaning loss: (1) patients might benefit from psychoeducation comprising the various Mil domains, (2) positive activity plans might be implemented to promote meaning-giving areas, and (3) imbalances can be identified and might be influenced using cognitive-behavioral or other psychological support.

Some 22 aspects (41.4\%) were not assigned to categories, as they may reflect more subjective and nonuniversal aspects of MiL experience. It is important to keep in mind that MiL experience can still be described as individual experiences using idiographic approaches. The resulting categories and domains of this model only reflect the universal portion of MiL experience that can be used for interindividual comparisons. The strength of idiographic instruments is to explore individual experiences that will not comprehensively fit into classes, which will need to be reported in addition to the universal MiL aspects.

The current study shows that the chosen methodology was able to identify a latent MiL structure, and can now be applied to further studies. The new 
categories and the circumplex model may be a first step toward improving the understanding of prevalent MiL areas and to help integrate the large number of different approaches to this construct.

\section{ACKNOWLEDGMENTS}

The authors are grateful to Olga Hildebrandt for her statistical support.

\section{CONFLICTS OF INTEREST}

The authors declare that they have no conflicts of interest to declare.

\section{REFERENCES}

Brandstätter, M., Baumann, U., Borasio, G.D., et al. (2012). Systematic review of meaning in life assessment instruments. Psycho-Oncology, 21(10), 1034-1052.

Brandstätter, M., Kögler, M., Baumann, U., et al. (2014). Experience of meaning in life in bereaved informal caregivers of palliative care patients. Supportive Care in Cancer, 22(5), 1391-1399.

Breitbart, W., Rosenfeld, B., Gibson, C., et al. (2010). Meaning-centered group psychotherapy for patients with advanced cancer: A pilot randomized controlled trial. Psycho-Oncology, 19(1), 21-28.

Burbank, P.M. (1992). An exploratory study: Assessing the meaning in life among older adult clients. Journal of Gerontological Nursing, 18(9), 19-28.

Chochinov, H.M., Hack, T., Hassard, T., et al. (2005). Dignity therapy: A novel psychotherapeutic intervention for patients near the end of life. Journal of Clinical Oncology, 23(24), 5520-5525.

Debats, D. (1999). Sources of meaning: An investigation of significant commitments in life. Journal of Humanistic Psychology, 39(4), 30-57.

DeVogler, K. \& Ebersole, P. (1980). Categorization of college students' meaning of life. Psychological Reports, 46, $387-390$.

DeVogler, K. \& Ebersole, P. (1983). Young adolescents' meaning in life. Psychological Reports, 52, 427-431.

Dittmann-Kohli, F. \& Westerhof, G.J. (1997). The SELESentence Completion Questionnaire: A new instrument for the assessment of personal meanings in aging research. Anuario de Psicologia, 73(2), 7-18.

Ebersole, P. \& DePaola, S. (1987). Meaning in life categories of later life couples. The Journal of Psychology, 121(2), 185-191.

Fegg, M., Kögler, M., Abright, C., et al. (2013). Meaning in life in patients with progressive supranuclear palsy. The American Journal of Hospice \& Palliative Care, 31(5), 543-547.

Fegg, M., Kögler, M., Brandstätter, M., et al. (2010). Meaning in life in patients with amyotrophic lateral sclerosis. Amyotrophic Lateral Sclerosis, 11(5), 469-474.

Fegg, M., Kramer, M., Bausewein, C., et al. (2007). Meaning in life in the Federal Republic of Germany: Results of a representative survey with the Schedule for Meaning in Life Evaluation (SMiLE). Health and Quality of Life Outcomes, 5, 59.
Fegg, M., Kramer, M., l'Hoste, S., et al. (2008). The Schedule for Meaning in Life Evaluation (SMiLE): Validation of a new instrument for meaning-in-life research. Journal of Pain and Symptom Management, 4, 356-363.

Frankl, V. (1958). The will to meaning. Journal of Pastoral Care, 12, 82-88.

Kernes, J.L. \& Kinnier, R.T. (2008). Meaning in psychologists' personal and professional lives. Journal of $\mathrm{Hu}$ manistic Psychology, 48(2), 196-220.

Kissane, D., Clarke, D. \& Street, A. (2001). Demoralization syndrome: A relevant psychiatric diagnosis for palliative care. Journal of Palliative Care, 17(1), 12-21.

Kudla, D., Kujur, J., Tigga, S., et al. (2014). Meaning in life experience at the end of life: Validation of the Hindi version of the Schedule for Meaning in Life Evaluation and a crosscultural comparison between Indian and German palliative care patients. Journal of Pain and Symptom Management, 49(1), 79-88.

Lethborg, C., Aranda, S., Cox, S., et al. (2007). To what extent does meaning mediate adaptation to cancer? The relationship between physical suffering, meaning in life, and connection to others in adjustment to cancer. Palliative \& Supportive Care, 5(4), 377-388.

McKnight, P.E. \& Kashdan, T.B. (2009). Purpose in life as a system that creates and sustains health and well-being: An integrative, testable theory. Review of General Psychology, 13(3), 242-251.

Meier, D., Emmons, C., Wallenstein, S., et al. (1998). A national survey of physician-assisted suicide and euthanasia in the United States. The New England Journal of Medicine, 338(17), 1193-1201.

Moadel, A., Morgan, C., Fatone, A., et al. (1999). Seeking meaning and hope: Self-reported spiritual and existential needs among an ethnically diverse cancer patient population. Psycho-Oncology, 8, 378-385.

Monforte-Royo, C., Tomás-Sábado, J., VillavicencioChávez, C., et al. (2011). Psychometric properties of the Spanish form of the Schedule for Meaning in Life Evaluation (SMiLE). Quality of Life Research, 20(5), 759-762.

Pohlmann, K., Gruss, B. \& Joraschky, P. (2006). Structural properties of personal meaning systems: A new approach to measuring meaning of life. The Journal of Positive Psychology, 1(3), 109-117.

Prager, E. (1996). Exploring personal meaning in an agedifferentiated Australian sample: Another look at the Sources of Meaning Profile (SOMP). Journal of Aging Studies, 10(2), 117-136.

Reker, G. \& Wong, P. (1988). Aging as an individual process: Towards a theory of personal meaning. In Emergent theories of aging. J. Birren \& V. Bengston (eds.), pp. 220-226. New York: Springer.

Rodriguez-Pereyra, G. (2008). Nominalism in metaphysics. In The Stanford encyclopedia of philosophy. E. Zalta E. (ed.). Available from http://plato.stanford.edu/archives/ spr2008/entries/nominalism-metaphysics/.

Schafer, J.L. (1996). Analysis of Incomplete Multivariate Data. http://www.amazon.com/Incomplete-MultivariateMonographs-Statistics-Probability/dp/0412040611.

Schnell, T. (2009). The Sources of Meaning and Meaning in Life Questionnaire (SoMe): Relations to demographics and well-being. The Journal of Positive Psychology, 4(6), 483-499.

Schwartz, S.H., Verkasalo, M., Antonovsky, A., et al. (1997). Value priorities and social desirability: Much 
substance, some style. British Journal of Social Psychology, 36(1), 3-18.

Sprangers, M. \& Schwartz, C. (1999). Integrating response shift into health-related quality of life research: A theoretical model. Social Science \& Medicine, 48(11), 1507-1515.

Stiefel, F., Krenz, S., Zdrojewski, C., et al. (2008). Meaning in life assessed with the Schedule for Meaning in Life Evaluation (SMiLE): A comparison between a cancer patient and student sample. Supportive Care in Cancer, 16(10), 1151-1155.

Takkinen, S. \& Ruoppila, I. (2001). Meaning in life in three samples of elderly persons with high cognitive function- ing. International Journal of Aging \& Human Development, 53(1), 51-73.

Wong, P. (1998). Implicit theories of meaningful life and the development of the personal meaning profile. In The human quest for meaning: A handbook of psychological research and clinical applications. P. Wong \& P. Fry (eds.), pp. 111-140. Mahwah, NJ: Lawrence Erlbaum.

Wong, P. \& Fry, P. (eds.) (1998). The human quest for meaning: A handbook of psychological research and clinical applications. Mahwah, NJ: Lawrence Erlbaum.

Yalom, I. (1980). Existential psychotherapy. New York: Basic Books. 